\title{
The Addition of Inhaled Budesonide to Standard Therapy Shortens the Length of Stay in Hospital for Asthmatic Preschool Children: A Randomized, Double-Blind, Placebo-Controlled Trial
}

\author{
Cem Hasan Razi ${ }^{a}$ Ahmet Zulfikar Akelma ${ }^{a}$ Koray Harmanci ${ }^{a}$ Mesut Kocak ${ }^{b}$ \\ Yasemin Kuras Can ${ }^{b}$ \\ ${ }^{a}$ Division of Pediatric Allergy and Immunology, Department of Pediatrics, and ${ }^{\mathrm{b}}$ Department of Pediatrics, \\ Keçiören Teaching and Research Hospital, Ankara, Turkey
}

\section{Key Words}

Asthma $\cdot$ Exacerbation $\cdot$ Inhaled budesonide $\cdot$ Hospital length of stay

\begin{abstract}
Background: Asthma exacerbations lead to frequent emergency visits and hospitalizations, and are associated with high morbidity and occasionally mortality. New therapeutic strategies are needed. We sought to investigate whether the addition of high-dose inhaled budesonide to standard therapy would shorten the length of stay (LOS) in hospital of children admitted for asthma exacerbations. Methods: The study was designed as a single-center, double-blind, placebo-controlled and parallel-group trial. Children aged 7-72 months and admitted with an asthma exacerbation clinical asthma score (CAS) of between 3 and 9 were allocated to either the budesonide $(n=50)$ or the placebo $(n=50)$ group. Hospital LOS was compared between children who received $2 \mathrm{mg} /$ day of budesonide versus placebo in addition to standard management of asthma exacerbation involving oxygen inhalation and $\beta_{2}$-agonist, anticholinergic and oral corticosteroid therapy. All patients were assessed every $4 \mathrm{~h}$. Children with a CAS $<3$, a peripheral oxygen saturation $>95 \%$
\end{abstract}

and normal pulmonary function, and those with a symptomfree period of at least $4 \mathrm{~h}$ after salbutamol treatment were discharged. Results: Total hospital LOS was significantly shorter in the budesonide group than in the placebo group (median: 44 vs. $80 \mathrm{~h}$, respectively; $\mathrm{p}=0.01$ ). When compared with placebo, the number of inpatients was significantly less in the budesonide group at all the assessed end points (Kaplan-Meier; $p=0.022$ ). Additionally, nebulized budesonide was found to reduce the overall cost of treatment. Conclusion: We demonstrated that, for children hospitalized for asthma exacerbations, an additional $2 \mathrm{mg} /$ day of nebulized budesonide significantly reduced hospital LOS as well as the overall cost of treatment.

(c) 2015 S. Karger AG, Basel

\section{Introduction}

Asthma is the most common chronic pulmonary disease among children, with an overall incidence of about $30 \%$ in developed countries. Despite the advent of new diagnostic tests and treatments, asthma exacerbations still cause significant morbidity and mortality. While the frequency of these exacerbations depends on the type and severity of the

\section{KARGER 125}

(c) 2015 S. Karger AG, Base

$1018-2438 / 15 / 1664-0297 \$ 39.50 / 0$

E-Mail karger@karger.com

www.karger.com/iaa
Correspondence to: Dr. Ahmet Zulfikar Akelma

Department of Pediatrics, Kecioren Teaching and Research Hospital

Pınarbașı M. Sanatoryum C. Ardahan Sk. No:25

TR-06380 Keçiören, Ankara (Turkey)

E-Mail akelma@gmail.com 
disease itself and the level of disease control, the majority of patients experience a repeat attack on average every 3 years. Asthma exacerbations lead to frequent emergency visits and hospitalizations, and are associated with high morbidity and occasionally mortality. Additionally, they are a major burden on health care resources. Prompt management of these exacerbations in the emergency department (ED) or on admission is thus imperative [1-4].

Standard management involves oxygen inhalation and $\beta_{2}$-agonist, anticholinergic and oral corticosteroid (OCS) therapy. Inhaled corticosteroids (ICS) are considered the first line of therapy for chronic asthma $[2,5,6]$. Based on limited studies, several clinicians have recommended the use of high doses of ICS in the treatment of asthma exacerbations in the ED [5], but there is no study which has assessed their efficacy in hospitalized children so far.

Current treatment protocols for asthma exacerbations in hospitalized children involve the use of oxygen, $\beta_{2^{-}}$ agonists, anticholinergics and OCS. We hypothesized that the addition of high-dose inhaled budesonide to standard therapy would shorten the length of stay (LOS) in hospital of children admitted for asthma exacerbation, and that the shortening of the hospital LOS would also reduce the overall cost of treatment.

\section{Methods}

\section{Study Patients}

Children aged 7-72 months and with a clinical asthma score (CAS) of between 3 and 9 who were hospitalized for asthma exacerbations were enrolled in the study. Written informed consent was obtained from all parents. The study was initiated once approved by the local ethics committee in accordance with the Declaration of Helsinki. Inclusion criteria included a medical history of at least 4 wheezing attacks and a history of prophylactic ICS use for asthma. Children with chronic diseases (e.g. malnutrition, anatomic malformation of the respiratory tract, chronic lung or heart disease, gastroesophageal reflux disease and cystic fibrosis) and those with a history of chronic drug use (e.g. antiepileptics and immune suppressives) were excluded from the study.

Atopy in the asthma group was investigated using a skin-prick test and specific IgE measurements. If the skin test demonstrated a wheal with a mean diameter of at least $3 \mathrm{~mm}$ greater than that of a saline control, it was considered positive. Each child was tested with a core battery of allergens (e.g. dust mite, cockroach, cat, dog, mould, milk, egg, peanut and pollen from grass, trees and weeds) and a clinic-specific battery of locally relevant allergens (ALK Abelló, Hørsholm, Denmark).

\section{Study Design}

The study was designed as a single-center, double-blind, placebo-controlled, parallel-group trial. Children hospitalized for asthma exacerbations between September 2007 and January
2010 were enrolled in the study. Demographic data (age, gender and current asthma treatment) were documented upon admission. Children were initially classified into 2 groups based on a positive or negative asthma predictive index (API). Children who had had recurrent episodes of wheezing during the first 3 years of life and 1 of 2 major criteria (physician-diagnosed eczema or parental physician-diagnosed asthma) or 2 of 3 minor criteria (physician-diagnosed allergic rhinitis, wheezing without having a cold or peripheral eosinophilia $\geq 4 \%$ ) were defined as API positive [7].

All patients enrolled in the study were assigned consecutive numbers (double-blind code) in balanced blocks of 10 by using a random-allocation software computer program. An independent pediatrician prepared the randomization list. The double-blind codes of the treatment numbers were enclosed in opaque, sealed envelopes available to the researchers in the case of a serious adverse event. Sealed envelopes were recovered by the primary investigator (C.H.R.) upon completion of the trial. All investigators were blinded to group allocation until data analysis was completed. This study is registered at ClinicalTrials.gov (NCT00733473).

\section{Study Protocol}

Children presenting to the pediatric service with an asthma exacerbation CAS of between 3 and 9 and complying with the inclusion criteria were invited to participate in the study. Patients received $1 \mathrm{mg} / \mathrm{kg} /$ day intravenous (i.v.) methylprednisolone for up to 5 days, and $0.15 \mathrm{mg} / \mathrm{kg}$ of salbutamol (Ventolin ${ }^{\circledR}$ ) nebula every $4 \mathrm{~h}$ and ipratropium bromide (Atrovent ${ }^{\circledR}$ ) $250 \mu \mathrm{g}$ every $6 \mathrm{~h}$ for 2 days as standard of care. Children with a peripheral oxygen saturation $\left(\mathrm{SpO}_{2}\right) \leq 92 \%$ received oxygen treatment. Following enrollment, children assigned to the study group received budesonide $(1 \mathrm{mg} / 2 \mathrm{ml})$ and those in the control group received 2 doses of preservative-free normal sterile saline (NSS; $2 \mathrm{ml}$ ) placebo. The two types of syringes, covered with aluminum foil, were similar in appearance. The investigators and patients were blinded to group allocation and syringe content. Medications were administered by a nurse from the pediatric service; children in the treatment group received 2 doses of budesonide $(1 \mathrm{mg} / 2 \mathrm{ml})$ and the control group received NSS $(2 \mathrm{ml})$ for up to 5 days. The CAS, $\mathrm{SpO}_{2}$ levels and peak heart rates were documented every $4 \mathrm{~h}$. Discharge criteria were as follows: (1) CAS $<3$ points, (2) $\mathrm{SpO}_{2}>95 \%$, (3) good aeration, no/mild wheezing and minimal respiratory distress upon physical examination and (4) a symptom-free period of at least $4 \mathrm{~h}$ following salbutamol treatment.

\section{Study Outcome}

The primary outcome was the difference between groups in mean hospital LOS. Differences in CAS, factors associated with treatment response and cost analysis were denoted as secondary outcomes.

\section{Assessment of CAS}

We used a CAS validated for children aged 1-5 years and strongly correlated to drug-dose interval, hospital LOS and discharge $[8,9]$. The score includes 5 items: respiratory rate, wheezing, inspiratory-expiratory ratio, chest retraction and observed dyspnea. Each variable is scored as 0,1 or 2, and then summed to give a total score (a maximum of 10). The clinical scoring of asthma is presented in table 1. 


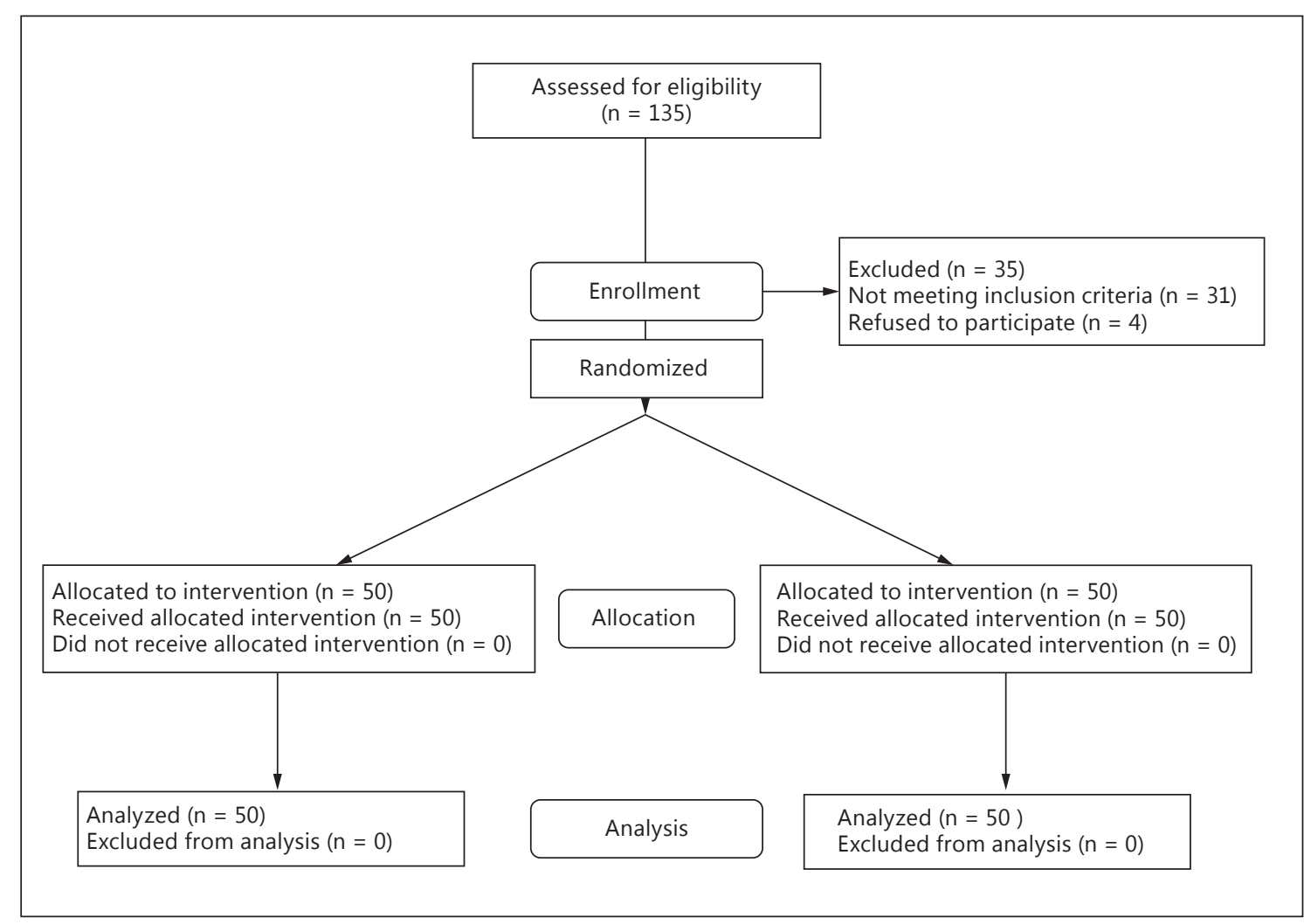

Fig. 1. Profile of patient recruitment and enrollment into the study.

Table 1. Clinical asthma score [8]

\begin{tabular}{|c|c|c|c|c|c|}
\hline Score & $\begin{array}{l}\text { Respiratory } \\
\text { rate }\end{array}$ & Wheezing & $\begin{array}{l}\mathrm{I} / \mathrm{E} \\
\text { ratio }\end{array}$ & $\begin{array}{l}\text { Chest } \\
\text { retraction }\end{array}$ & Dyspnea \\
\hline 0 & $<40$ & none & $\mathrm{I}>\mathrm{E}$ & none & none \\
\hline 1 & $40-60$ & $\mathrm{E}$ & $\mathrm{I}=\mathrm{E}$ & subcostal & mild \\
\hline 2 & $>60$ & $\mathrm{I}$ and $\mathrm{E}$ & $\mathrm{I}<\mathrm{E}$ & $\begin{array}{l}\text { sub- and } \\
\text { intercostal }\end{array}$ & severe \\
\hline
\end{tabular}

$\mathrm{I} / \mathrm{E}=$ Inspiratory/expiratory. Respiratory note was measured in breaths/min.

\section{Statistical Analysis}

Statistical analysis was performed with Statistical Package for Social Sciences 20.0 software (SPSS Inc., Chicago, Ill., USA). The Shapiro-Wilk test determined whether the distributions of continuous variables were normal or not. Continuous variables were expressed as a median (range). The median differences were compared by the Mann-Whitney U test. Nominal data were evaluated by the Pearson $\chi^{2}$ or the Fisher exact test, where appropriate. The comparison of inpatient numbers in the 2 groups was performed using the Kaplan-Meier analysis. A p value $<0.05$ was considered statistically significant.

Inhaled Budesonide Treatment for Hospitalized Asthmatic Children
Estimation of Sample Size

The primary aim of this study was to compare the 2 groups according to hospital LOS. A sample size of 47 per group was required to detect at least $18 \mathrm{~h}$ difference $(\mathrm{SD}=36.1)$ with a power of $80 \%$ at the $5 \%$ significance level. The difference of $18 \mathrm{~h}$ was taken from both the pilot study and from clinical experience. Sample size estimation was performed with NCSS and PASS 2000 software.

\section{Results}

During the study period, 135 children hospitalized with a diagnosis of moderate-to-severe asthma were eligible for inclusion. Of these, 31 were excluded because they did not meet the inclusion criteria and 4 because their parents did not consent, leaving a total of 100 patients enrolled. Patients' demographics and baseline characteristics are presented in figure 1 . Patients were randomized to receive either budesonide or placebo in a double-blind manner. The mean age, sex distribution, total duration of illness and number of emergency visits and hospitalizations in the previous year were similar in the 2 groups 
Table 2. Comparison of demographic features

\begin{tabular}{lccc}
\hline & $\begin{array}{l}\text { Budesonide } \\
\text { group } \\
(\mathrm{n}=50)\end{array}$ & $\begin{array}{l}\text { Placebo } \\
\text { group } \\
(\mathrm{n}=50)\end{array}$ & $\begin{array}{l}\mathrm{p} \\
\text { value }\end{array}$ \\
\hline Age, months & $19(7-72)$ & $18(8-59)$ & 0.8 \\
$\begin{array}{l}\text { Gender } \\
\quad \text { Male }\end{array}$ & $34(68.0)$ & $36(72.0)$ & 0.6 \\
$\quad$ Female & $16(32.0)$ & $14(28.0)$ & \\
Duration of asthma, months & $12(1-45)$ & $10(1-48)$ & 0.4 \\
Exacerbations in the last year & $4(1-10)$ & $4(1-11)$ & 0.3 \\
ED visits in the previous year & $4(2-10)$ & $4(2-10)$ & 0.1 \\
Hospitalizations in the previous & & & \\
$\quad$ year & $2(1-5)$ & $2(1-5)$ & 0.6 \\
Exposure to smoking & $23(46)$ & $30(60)$ & 0.1 \\
$\begin{array}{l}\text { Atopy } \\
\text { Atopic dermatitis }\end{array}$ & $10(20)$ & $14(28)$ & 0.3 \\
Family history of asthma & $11(22)$ & $9(18)$ & 0.6 \\
Positive API & $19(30)$ & $11(22)$ & 0.3 \\
\hline
\end{tabular}

Values are presented as $\mathrm{n}(\%)$ or median (range).

Table 3. Comparison of clinical features between groups

\begin{tabular}{lccl}
\hline & $\begin{array}{l}\text { Budesonide } \\
(\mathrm{n}=50)\end{array}$ & $\begin{array}{l}\text { Placebo } \\
(\mathrm{n}=50)\end{array}$ & $\begin{array}{l}\mathrm{p} \\
\text { value }\end{array}$ \\
\hline $\begin{array}{l}\text { Duration of symptoms in the } \\
\quad \text { previous episode, days }\end{array}$ & $3(1-19)$ & $3(1-15)$ & 0.8 \\
$\begin{array}{l}\text { URTI before wheezing, } \mathrm{n} \\
\mathrm{SPO}_{2} \text { at admission, \% }\end{array}$ & $39(78 \%)$ & $41(82 \%)$ & 0.6 \\
$\mathrm{CAS}$ at admission & $90(83-97)$ & $88(82-92)$ & 0.3 \\
Total length of stay, h & $7(5-9)$ & $7(6-9)$ & 0.8 \\
\hline
\end{tabular}

Values are median (range), unless otherwise indicated. The value in bold type denotes a statistically significant difference $(\mathrm{p}<$ 0.05). URTI $=$ Upper respiratory tract infections.

Table 4. Comparison of discharge rates between the groups at different end points

\begin{tabular}{lccc}
\hline Time point & $\begin{array}{c}\text { Budesonide } \\
(\mathrm{n}=50)\end{array}$ & $\begin{array}{c}\text { Placebo } \\
(\mathrm{n}=50)\end{array}$ & p value \\
\hline $24 \mathrm{~h}$ & $3(6.0)$ & $2(4.0)$ & 0.6 \\
$36 \mathrm{~h}$ & $12(24.0)$ & $10(20.0)$ & 0.6 \\
$48 \mathrm{~h}$ & $30(60.0)$ & $12(24.0)$ & $<\mathbf{0 . 0 0 1}$ \\
$60 \mathrm{~h}$ & $34(68.0)$ & $16(32.0)$ & $<\mathbf{0 . 0 0 1}$ \\
$72 \mathrm{~h}$ & $38(76.0)$ & $24(48.0)$ & $\mathbf{0 . 0 0 4}$ \\
$96 \mathrm{~h}$ & $40(80.0)$ & $34(68.0)$ & 0.1 \\
$120 \mathrm{~h}$ & $44(88.0)$ & $41(82.0)$ & 0.4 \\
$144 \mathrm{~h}$ & $50(100.0)$ & $46(92.0)$ & $\mathbf{0 . 0 4}$ \\
$168 \mathrm{~h}$ & $50(100.0)$ & $48(96.0)$ & 0.1 \\
\hline
\end{tabular}

Values denote $\mathrm{n}(\%)$. Values in bold type denote statistically significant differences $(\mathrm{p}<0.05)$.

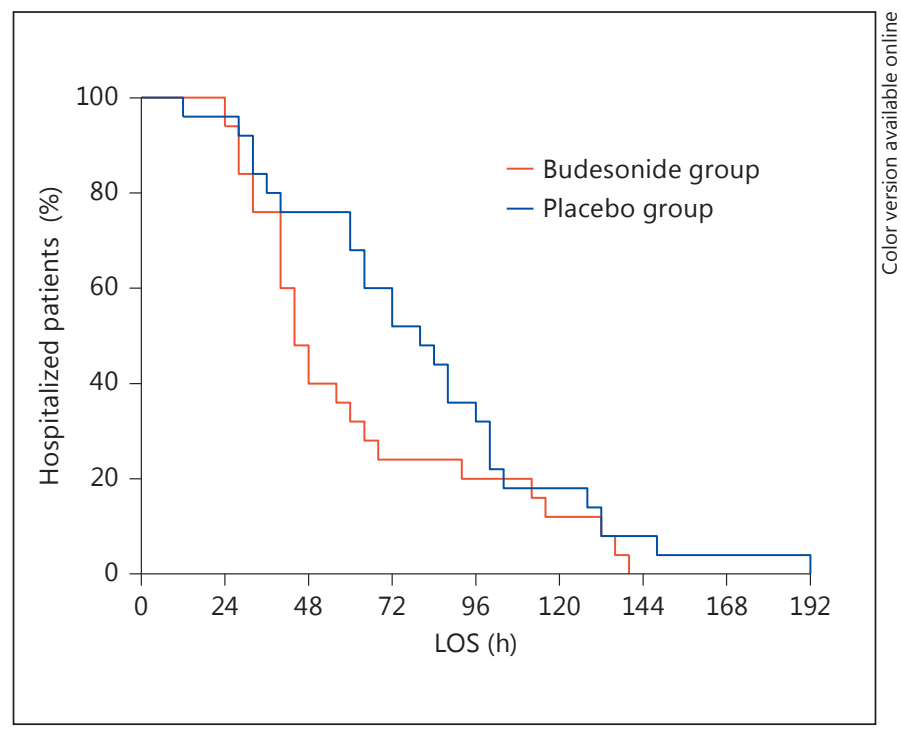

Fig. 2. Comparison of inpatient percentages between the budesonide and placebo groups during the study period. The comparison was performed using Kaplan-Meier analysis $(\mathrm{p}=0.028)$. Note that percentages were lower in the budesonide group between 48 and $72 \mathrm{~h}$ and at $144 \mathrm{~h}$.

$(p>0.05)$. The rate of atopy, the history of atopic dermatitis, family history of asthma and positive API did not differ significantly between groups ( $p>0.05$; table 2 ). The groups were also well-matched with regard to the duration of symptoms and the rate of upper respiratory tract infection before admission, CAS upon admission and $\mathrm{SpO}_{2}$ levels ( $\mathrm{p}>0.05)$. Total hospital LOS was significantly shorter for children in the budesonide group than the placebo group (median: 44 vs. $80 \mathrm{~h}$, respectively; $\mathrm{p}=0.01$; table 3 ).

Discharge rates were compared at several end points. While discharge rates were similar between the groups at 36 h (12 vs. 10 patients; $p>0.05$ ), they were significantly higher in the budesonide group at 48,60 and $72 \mathrm{~h}$ (i.e. 30 vs. 12,34 vs. 16 and 38 vs. 24 patients, respectively; $\mathrm{p}<$ $0.01)$. As the number of inpatients decreased, i.e. after $96 \mathrm{~h}$, the difference was no longer significant $(\mathrm{p}>0.05)$. Of note, at $144 \mathrm{~h}$, the total number of discharged children was significantly higher in the budesonide group than in the placebo group ( $\mathrm{p}=0.04$; table 4$)$. Hospital LOS was significantly shorter in the budesonide than in the placebo group ( $\mathrm{p}=0.028$; fig. 2 ). $\mathrm{CAS}, \mathrm{SpO}_{2}$ and heart and respiratory rates in the first $96 \mathrm{~h}$ are presented in figure 3.

The cost of standard care of patients admitted for asthma exacerbations in Turkey is around USD 100 for $24 \mathrm{~h}$. The approximate daily cost of treatment with budesonide (4 nebulae of $1 \mathrm{mg} / 2 \mathrm{ml}$ ) is USD 5 (median hospital LOS: 

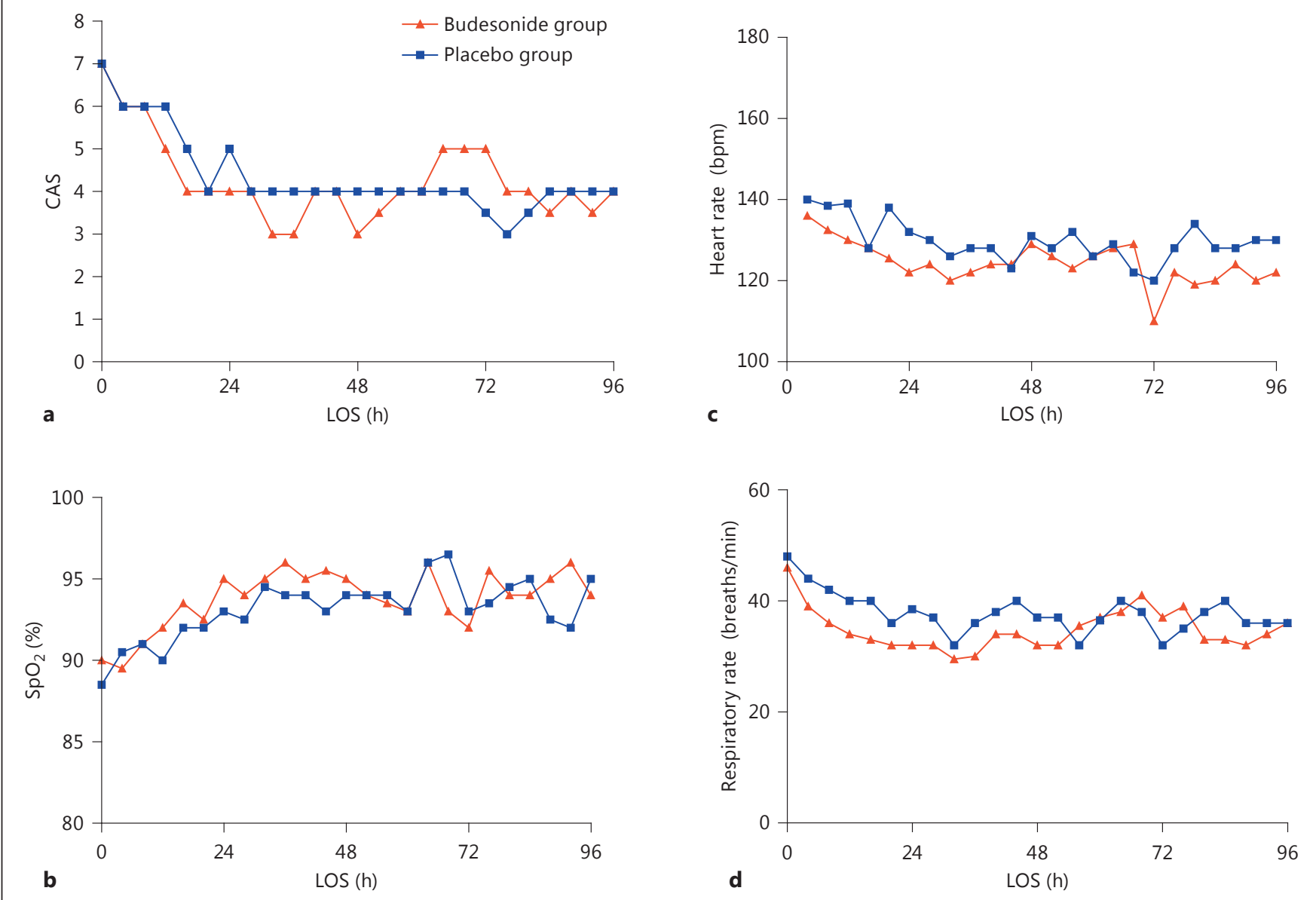

Fig. 3. Presentation of median CAS (a), $\mathrm{SpO}_{2}$ (b), heart rates (c) and respiratory rates $(\mathbf{d})$ of patients in the budesonide and placebo groups during the 96-hour follow-up. Because healed patients were consistently discharged, the data at each end point reflect the results of analysis performed on the patients not yet discharged.
Therefore, a between-group statistical comparison was not performed. Nevertheless, the CAS, heart and respiratory rates seemed to be lower and the $\mathrm{SpO}_{2}$ higher in the budesonide group than in the placebo group.
$44 \mathrm{~h})$. Given the fact that the median hospital LOS for patients in the budesonide group was $36 \mathrm{~h}$ shorter than the placebo group, the cost of treatment for a patient treated with budesonide was USD 130 less than for a patient in the placebo group. No drug-related adverse effects were identified during hospitalization.

\section{Discussion}

We identified that $2 \mathrm{mg} /$ day of budesonide added to standard care shortened the hospital LOS by $36 \mathrm{~h}$ for children hospitalized due to asthma exacerbation. We also found that ICS significantly reduced the overall cost of treatment for children with asthma exacerbations, owing, particularly, to a reduction in hospital LOS. The cost for each child treated with budesonide was USD 130 less than for children who did not receive budesonide.

Exacerbations, emergency visits and hospitalization are common among children with asthma. In the study by Rabe et al. [4], 57\% of children with asthma experienced symptoms consistent with asthma exacerbation in the previous month, $28 \%$ suffered an unforeseen attack, $18 \%$ presented to the ED and $75 \%$ had a history of hospitalization. On the economic side, asthma treatment constitutes a major burden on health care resources [10] and 
causes absence from work by the parents of the asthmatic children. So shortening the hospital LOS by $36 \mathrm{~h}$ provides significant social and economic benefits.

Treating asthma exacerbations with ICS is faster than with OCS [11]. Moreover, single-dose fluticasone has been shown to reduce airway responsiveness within $2 \mathrm{~h}$ [12]; this partially explains the positive effects of ICS on hospital LOS. Given the fact that OCS are already efficient in the treatment of asthma exacerbations, their combination with ICS in the treatment of moderate-to-severe exacerbations may be considered the treatment of choice [11]. While daily ICS use for asthma prophylaxis is common, several authors recommend ICS for the management of acute exacerbations [13-15], having assessed their efficacy in the ED setting. Recently, Chen et al. [16] demonstrated that the use of nebulized corticosteroids $(1,500$ $\mu \mathrm{g})$ in the first hour of ED presentation facilitated better clinical healing than when placebo was administered to patients experiencing a moderate-to-severe asthma exacerbation. This study demonstrated that early use of ICS may prove efficient in the ED treatment of asthma exacerbation. Several studies have compared ICS to OCS in asthma exacerbation treatment. Volovitz et al. [17] compared a single dose of oral prednisone $(2 \mathrm{mg} / \mathrm{kg})$ to a dose every $4 \mathrm{~h}$ for 1 week with a $1,600-\mu \mathrm{g}$ budesonide turbuhaler in children with asthma exacerbations presenting to the ED, and found that the CAS and pulmonary functions were similar. They also found that ICS decreased serum cortisol concentration. Schuh et al. [18], on the other hand, found that OCS administration ( $2 \mathrm{mg} / \mathrm{kg}$ oral prednisone) reduced hospitalization rates and improved $\mathrm{FEV}_{1}$ significantly more than ICS $(2,000 \mu \mathrm{g}$ of fluticasone propionate) in children $>5$ years old with moderate-to-severe asthma.

Studies assessing the efficacy of a combination of OCS and ICS for the treatment of asthma in children are lim- ited and usually conducted in the ED setting. Alangari et al. [19] conducted a study on children aged 2-12 years who were diagnosed with asthma exacerbation in the ED. They compared the admission rates between children who received $1,500 \mu \mathrm{g}$ budesonide versus children who received placebo; both groups received salbutamol, ipratropium bromide and a single dose of $2 \mathrm{mg} / \mathrm{kg}$ of prednisolone). Overall, the admission rates did not differ. When stratified according to disease severity, however, there was a lower rate of admission for children with severe asthma (CAS $\geq 13$ ) who received budesonide. Upham et al. [20] demonstrated that when a single dose of $2 \mathrm{mg}$ of budesonide was added to standard therapy, the CAS did not improve and admission rates were not reduced in comparison to placebo treatment.

Guideline recommendations on the use of ICS in children with asthma exacerbations are limited to the ED. While The Global Initiative for Asthma (GINA) report recommends the use of ICS in the first hour of treatment for children aged $>5$ years with asthma exacerbation in the ED, it also states that the evidence that the combination of ICS and OCS therapy improves pulmonary function or CAS in acute exacerbations is insufficient (this is because the administration of ICS reduces admission rates) [5]. Results concerning the benefits of ICS therapy for asthma exacerbation in small children are conflicting.

To conclude, we demonstrated that an additional 2 $\mathrm{mg}$ /day of nebulized budesonide administered to children hospitalized for asthma exacerbations significantly reduced hospital LOS and the overall cost of treatment. Given the social and economic implications of this finding, adding this budesonide dose to standard care may indeed be an option in the future for the treatment of children hospitalized for asthma exacerbations.

\section{References}

1 Jackson DJ, Sykes A, Mallia P, Johnston SL: Asthma exacerbations: origin, effect, and prevention. J Allergy Clin Immunol 2011;128: 1165-1174.

$\checkmark 2$ Papadopoulos NG, Arakawa H, Carlsen KH, et al: International Consensus on (ICON) Pediatric Asthma. Allergy 2012;67:976-997.

>3 Tsai CL, Lee WY, Hanania NA, Camargo CA Jr: Age-related differences in clinical outcomes for acute asthma in the United States, 2006-2008. J Allergy Clin Immunol 2012;129: 1252-1258.e1.

-4 Rabe KF, Vermeire PA, Soriano JB, Maier WC: Clinical management of asthma in 1999: the Asthma Insights and Reality in Europe (AIRE) study. Eur Respir J 2000;16:802-807.

5 From the Global Strategy for Asthma Management and Prevention, Global Initiative for Asthma (GINA) 2014. http://www.ginasthma.org/.

6 National Heart, Lung, and Blood Institute: National Asthma Education and Prevention Program Expert Panel Report 3: Guidelines for the Diagnosis and Management of Asthma. Bethesda, National Institutes of Health, 2007.

7 Castro-Rodriguez JA, Holberg CJ, Wright AL, Martinez FD: A clinical index to define risk of asthma in young children with recurrent wheezing. Am J Respir Crit Care Med 2000; 162:1403-1406.

$>8$ Parkin PC, Macarthur C, Saunders NR, Diamond SA, Winders PM: Development of a clinical asthma score for use in hospitalized children between 1 and 5 years of age. J Clin Epidemiol 1996;49:821-825.

-9 Goggin N, Macarthur C, Parkin PC: Randomized trial of the addition of ipratropium bromide to albuterol and corticosteroid therapy in children hospitalized because of an acute asthma exacerbation. Arch Pediatr Adolesc Med 2001;155:1329-1334.
Razi/Akelma/Harmanci/Kocak/

Kuras Can 
10 Barnett SB, Nurmagambetov TA: Costs of asthma in the United States: 2002-2007. J Allergy Clin Immunol 2011;127:145-152.

- 11 Belda J, Margarit G, Martinez C, BellidoCasado J, Casan P, Torrejon M, Brufal M, Rodriguez-Jerez F, Sanchis J: Anti-inflammatory effects of high-dose inhaled fluticasone versus oral prednisone in asthma exacerbations. Eur Respir J 2007;30:1143-1149.

12 Ketchell RI, Jensen MW, Lumley P, Wright AM, Allenby MI, O'Connor BJ: Rapid effect of inhaled fluticasone propionate on airway responsiveness to adenosine $5^{\prime}$-monophosphate in mild asthma. J Allergy Clin Immunol 2002;110:603-606.

$\checkmark 13$ Chauhan BF, Chartrand C, Ducharme FM: Intermittent versus daily inhaled corticosteroids for persistent asthma in children and adults. Cochrane Database Syst Rev 2013; 2:CD009611.

14 Zeiger RS, Mauger D, Bacharier LB, Guilbert TW, Martinez FD, Lemanske RF Jr, Strunk RC, Covar R, Szefler SJ, Boehmer S, Jackson DJ, Sorkness CA, Gern JE, Kelly HW, Fried- man NJ, Mellon MH, Schatz M, Morgan WJ, Chinchilli VM, Raissy HH, Bade E, MalkaRais J, Beigelman A, Taussig LM: Daily or intermittent budesonide in preschool children with recurrent wheezing. N Engl J Med 2011; 365:1990-2001.

15 FitzGerald JM, Shragge D, Haddon J, Jennings B, Lee J, Bai T, Pare P, Kassen D, Grunfeld A: A randomized, controlled trial of high dose, inhaled budesonide versus oral prednisone in patients discharged from the emergency department following an acute asthma exacerbation. Can Respir J 2000;7: 61-67.

16 Chen AH, Zeng GQ, Chen RC, Zhan JY, Sun LH, Huang SK, Yang CZ, Zhong N: Effects of nebulized high-dose budesonide on moderate-to-severe acute exacerbation of asthma in children: a randomized, double-blind, placebo-controlled study. Respirology 2013; 18(suppl 3):47-52.

17 Volovitz B, Bentur L, Finkelstein Y, Mansour Y, Shalitin S, Nussinovitch M, Varsano I: Effectiveness and safety of inhaled corticoste- roids in controlling acute asthma attacks in children who were treated in the emergency department: a controlled comparative study with oral prednisolone. J Allergy Clin Immunol 1998; 102:605-609.

18 Schuh S, Reisman J, Alshehri M, Dupuis A, Corey M, Arseneault R, Alothman G, Tennis $\mathrm{O}$, Canny G: A comparison of inhaled fluticasone and oral prednisone for children with severe acute asthma. N Engl J Med 2000;343: 689-694.

19 Alangari AA, Malhis N, Mubasher M, AlGhamedi N, Al-Tannir M, Riaz M, Umetsu DT, Al-Tamimi S: Budesonide nebulization added to systemic prednisolone in the treatment of acute asthma in children: a doubleblind, randomized, controlled trial. Chest 2014; 145:772-778.

20 Upham BD, Mollen CJ, Scarfone RJ, Seiden J, Chew A, Zorc JJ: Nebulized budesonide added to standard pediatric emergency department treatment of acute asthma: a randomized, double-blind trial. Acad Emerg Med 2011;18:665-673. 